\title{
Ultrastructural variation of cultured Ehrlichia chaffeensis
}

\author{
V. L. POPOV, SHENG-MIN CHEN, HUI-MIN FENG and D. H. WALKER* \\ Department of Pathology, University of Texas Medical Branch, Galveston, TX 77555-0609, USA
}

\begin{abstract}
Summary. The ultrastructure of Ehrlichia chaffeensis (Arkansas strain) was studied in nonirradiated and irradiated monolayers of mouse embryo, Vero, BGM and L929 cells, and in non-irradiated DH82 cells. Within the intracellular parasitophorous vacuoles (morulae), two types of ehrlichial cells were found regularly - those with uniformly dispersed nucleoid filaments and ribosomes (reticulate cells) and smaller ones with centrally condensed nucleoid filaments and ribosomes (dense-cored cells), which represent the normal life cycle of ehrlichiae. In addition, large reticulate cells were observed, forming long projections of the cell wall, protrusions of cytoplasmic membrane into the periplasmic space, or budding of protoplast fragments (minute forms) into the periplasmic space. Ehrlichiae with abnormalities of protoplast fission were found, apparently leading to formation of giant, multilobular or elongated rod-like ehrlichiae. Morulae were usually surrounded by cisterns of granular endoplasmic reticulum and mitochondria and often contained vesicles, long tubules $25 \mathrm{~nm}$ in diameter, probably originating from the ehrlichial cell wall, and fibrillar ehrlichial antigen apparently shed from the surface of the cell wall. Some cells contained, in addition to normal morulae, a whole morula that had become dense and contained degenerating ehrlichiae. These results indicate that as well as normal growth and reproduction, ehrlichiae exhibit pathological events: they can be remarkably damaged inside the host cell vacuoles, presumably phagolysosomes, or enter a process morphologically similar to bacterial L-transformation.
\end{abstract}

\section{Introduction}

Ehrlichiae are obligately parasitic intracellular bacteria classified in the tribe Ehrlichieae of the family Rickettsiaceae, order Rickettsiales. ${ }^{1}$ The genus Ehrlichia contains at least eight recognised species- $E$. canis, E. chaffeensis, E. ewingii, E. equi, E. phagocytophila, E. risticii, E. sennetsu, E. muris- ${ }^{2-5}$ and some organisms that have not been fully characterised-E. platys, E. bovis, E. ondiri, E. ovina and $E$. microti. ${ }^{4}$ Those organisms for which a vector is known are transmitted by ticks, and most are pathogenic for animals including dogs, horses and cattle; however, $E$. sennetsu, E. chaffeensis and an E. phagocytophila-like organism $^{6}$ are pathogens for man. All ehrlichiae multiply in leucocytes, usually either granulocytes or macrophages/monocytes. There they reside within cytoplasmic vacuoles, which are referred to as morulae and are derived from the initial endosome.

Ehrlichiae are extremely difficult to cultivate in vitro; usually macrophage-like cell lines are used for

Received 11 Oct. 1994; revised version accepted 28 April 1995.

* Correspondence should be sent to Dr D. H. Walker. this purpose. ${ }^{4}$ Recently, several groups have succeeded in propagating ehrlichiae in continuous cell lines of other origins: $E$. canis in a continuous human endothelial cell line, ${ }^{7} E$. risticii in a human intestinal epithelial cell line (T-34), ${ }^{8}$ E. sennetsu in L929 cells (mouse fibroblasts) $^{9}$ and a human amniotic membrane-derived cell line, FL, ${ }^{10} E$. chaffeensis in Vero, mouse embryo, BGM, L929 and HeLa cells, human embryonic lung fibroblasts (HEL 299) and a continuous human endothelial cell line. ${ }^{7,11,12}$

The ultrastructure of the members of the genus Ehrlichia has been described briefly for $E$. sennetsu, ${ }^{13,14}$ E. canis, ${ }^{15,16}$ E. equi, ${ }^{17}$ E. muris ${ }^{5}$ and E. risticii. ${ }^{14,18,19}$ There are very limited data about the submicroscopic morphology of these organisms and the details of their interaction with the host cells, especially for $E$. chaffeensis. ${ }^{11}$ The main obstacle has been the difficulty of cultivation in vitro in amounts suitable for electronmicroscopic examination.

The ultrastructure of $E$. chaffeensis recently adapted in this laboratory to continuous cell lines including mouse embryo, Vero, BGM and L929 cells ${ }^{12}$ was studied and its development in these cells was compared with that in DH82 cells. This report presents the 
normal anatomy of this intracellular bacterium, variations in its morphology that appear to represent ehrlichial pathology. and the different modes of its interaction with the host cells.

\section{Materials and methods}

\section{Cell lines}

DH82 cells were cultivated in Eagle's minimum essential medium (EMEM) supplemented with bovine calf serum $10 \%$. Other cell lines, i.e., mouse embryo cells provided by T. R. Jerrells, Vero (ATCC CCL 81), BGM (Viromed Laboratories, Inc., Minneapolis, MN, USA) and L929 cells (ATCC CCL1.2) were cultivated in EMEM with bovine calf serum $5 \%$. The cells were placed into 24-well plates (Falcon; Becton-Dickinson Labware, Lincoln Park, NJ, USA) at a concentration of $2 \times 10^{5}$ cells $/$ well. The cell lines were either untreated or $\gamma$-irradiated at 3000 rads before being seeded on to the plates. The cells were incubated at $37^{\circ} \mathrm{C}$ in an atmosphere containing $\mathrm{CO}_{2} 5 \%$ for $24 \mathrm{~h}$.

\section{Cultitation of $E$. chaffeensis}

E. chaffeensis, Arkansas strain, was generously provided by Jacqueline Dawson. Viral and Rickettsial Zoonoses Branch, Centers for Disease Control and Prevention (CDC), Atlanta, GA, USA, and was propagated in DH82 cells as described previously. ${ }^{12}$ Monolayers of DH82, mouse embryo. BGM and Vero cells in 24-well plates were inoculated with $0.2 \mathrm{ml}$ of $E$. chaffeensis suspension, freed from host cells, in serial 10 -fold dilutions in growth medium containing fetal calf serum (FCS) $5 \%$. To prepare control cells, $0.2 \mathrm{ml}$ of the same medium was added after removal of the old medium from the plates. The plates were centrifuged at $1000 \mathrm{~g}$ for $1 \mathrm{~h}$ at $30^{\circ} \mathrm{C}$ and then incubated at $37^{\circ} \mathrm{C}$ in air with $\mathrm{CO}_{2} 5 \%$ for $3 \mathrm{~h}$. Infected and control DH82 cells were cultivated in growth medium containing FCS $10 \%$. Other cells lines were fed with growth medium with FCS $5 \%, 1 \mathrm{ml} /$ well. The intracellular growth of ehrlichiae was monitored by Romanovsky staining (LeukoStat ${ }^{\mathbb{R}}$, Fisher Scientific, Pittsburgh. PA, USA) and indirect immunofluorescence (IF) on days 5 and 10 . The supernate in each well was removed, and $0.5 \mathrm{ml}$ of PBS with sodium azide $0 \cdot 1 \%$ and bovine calf serum $2 \%$ was added to each well to inactivate the ehrlichiae. After $1.5 \mathrm{~h}$, the cells were scraped from the bottom of the wells with pipette tips and were pipetted repeatedly to prepare a cell suspension. The cell suspensions were used for cytospin preparations, which were examined by Romanovsky and IF staining.

\section{Electronmicroscopy.}

The cells in the wells were fixed in a mixture of formaldehyde $1.25 \%$, glutaraldehyde $2.5 \%$ and trini- trophenol $0.03 \%$ in $0.05 \mathrm{M}$ cacodylate buffer, $\mathrm{pH} 7 \cdot 3,{ }^{20}$ postfixed in $\mathrm{OsO}_{4} 1 \%$, stained en bloc with uranyl acetate $1 \%$ in $0.1 \mathrm{~m}$ maleate buffer, $\mathrm{pH} 5.2$, dehydrated in ethanol and embedded in Poly/Bed 812 (Polysciences Inc., Warrington, PA, USA). Plastic blocks were removed from the wells by breaking the latter in liquid nitrogen; specimens were cut out and glued to blank epoxy blocks. Thin sections were cut with a Sorvall MT-6000 ultramicrotome and stained with uranyl acetate and lead citrate. The specimens were examined in a Philips 201 electronmicroscope.

For post-embedding immuno-electronmicroscopy, infected monolayers were fixed in Ito's fixative modified according to Berryman and Rodewald. ${ }^{21}$ The modification involved lowering the concentration of glutaraldehyde to $0.5 \%$ and raising that of formaldehyde to $2.5 \%$. After post-fixation in uranyl acetate $1 \%$ in $0.1 \mathrm{M}$ maleate buffer, $\mathrm{pH} 5 \cdot 2$, and extensive washing in the same buffer, the cells were dehydrated in ethanol $50 \%$ and $75 \%$ and embedded into medium grade LR White resin (Structure Probe, West Chester, PA, USA). Ultra-thin sections mounted on Formvar and carbon-coated nickel grids were incubated for $1 \mathrm{~h}$ at room temperature and then overnight at $4^{\circ} \mathrm{C}$ in polyclonal canine or rabbit anti-E. chaffeensis serum diluted 1 in 10 in $0.01 \mathrm{M}$ PBS containing bovine serum albumin (BSA) $1 \%$, and then treated with protein Agold $\left(15 \mathrm{~nm}\right.$, AuroProbe ${ }^{\mathrm{m}} \mathrm{EM}$ protein $\mathrm{A}$ G15; Amersham Life Science, Arlington Heights, IL, USA) for $30 \mathrm{~min}$ at room temperature. The protein A-gold probe was diluted 1 in 10 in $0.01 \mathrm{M}$ PBS containing BSA $1 \%$. Preparations were washed in $0.01 \mathrm{M}$ PBS containing BSA $0.1 \%$ and $0.01 \mathrm{M}$ glycine before and after incubation with the primary antibody to prevent non-specific staining.

\section{Results}

\section{General observations}

Electronmicroscopic examination showed that the greatest quantities of intracellular vacuoles containing ehrlichiae (morulae) were found in mouse embryo cells and DH82 cells. Sometimes individual host cells harboured $>400$ small morulae $(1.0-1.5 \mu \mathrm{m}$ in diameter, each containing from one to five ehrlichiae) in the plane of one ultra-thin section.

There were neither differences in the ultrastructure of ehrlichiae nor any peculiarities of their interaction with non-irradiated or irradiated host cells, and also the differences in ehrlichial morphology could not be related to the initial dilution of the inoculum (from undiluted to $10^{3}$ ).

\section{Ultrastructure of ehrlichial cells}

Ehrlichial cells found inside the morulae showed two apparently normal morphological types: (1) large, mostly oval, but sometimes round cells with evenly distributed ribosomes and nucleoid DNA 


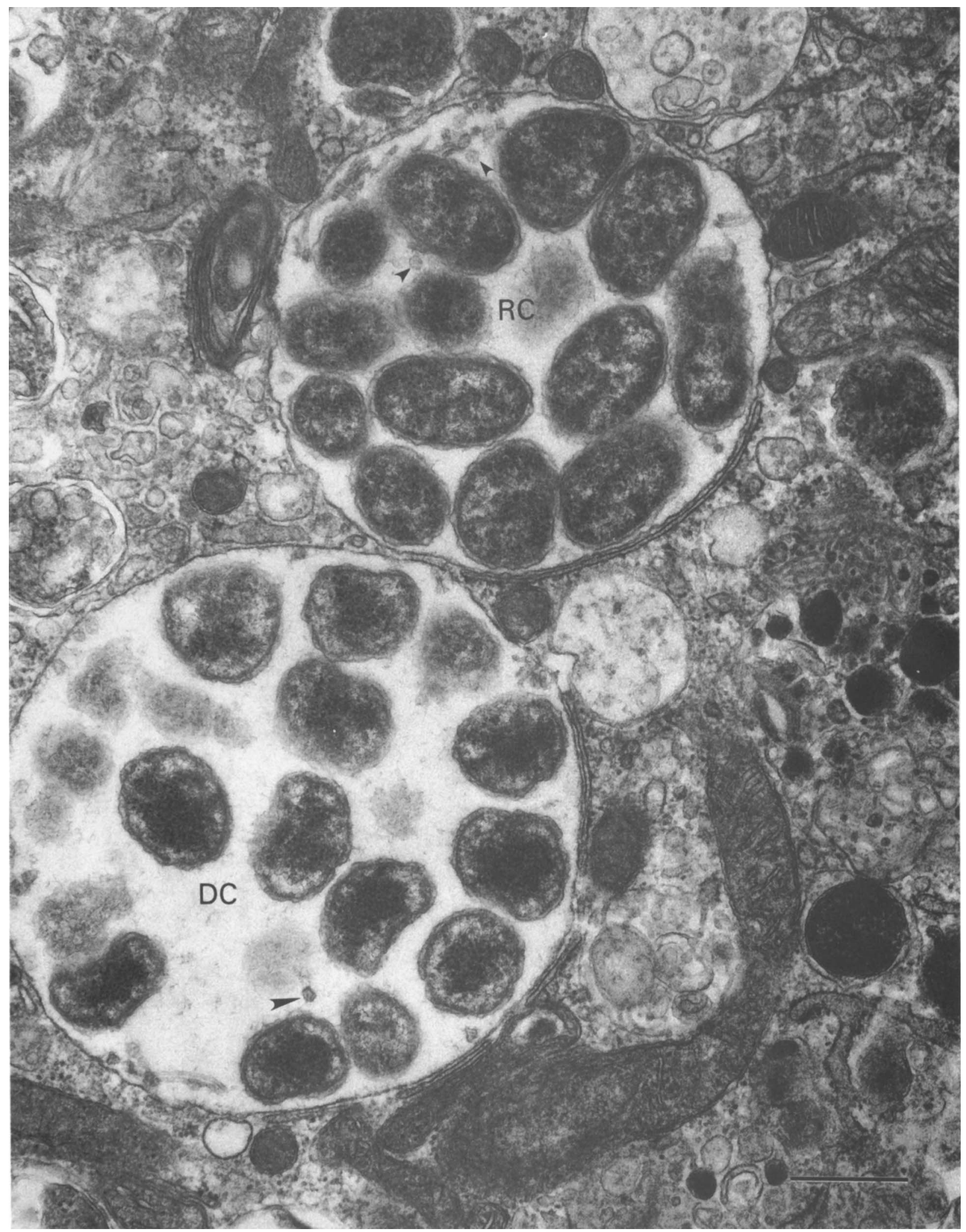

Fig. 1. Two morulae of $E$. chaffeensis with populations of either reticulate cells (RC) or dense-cored (DC) cells in the cytoplasm of an irradiated mouse embryo cell (inoculum dilution $10^{2}$ ). Intramorular matrix contains tiny fibrils, vesicles $(\longrightarrow)$ and tubules. Cisterns of granular endoplasmic reticulum surround part of morula membrane, forming tight contacts with it. Mitochondria are characteristically located near the morulae. Bar $=0.5 \mu \mathrm{m}$.

fibrils; (2) cells having an electron-dense central concentration of ribosomes and DNA fibrils with peripheral more loosely distributed DNA fibrils (fig. 1). In addition, cells of both morphological types were observed with numerous alterations that probably represent ehrlichial responses to injury.

The size of the first type of cells was usually within the limits of $0.4-0.6 \mu \mathrm{m}$ by $0.7-1.9 \mu \mathrm{m}$. Some of these 


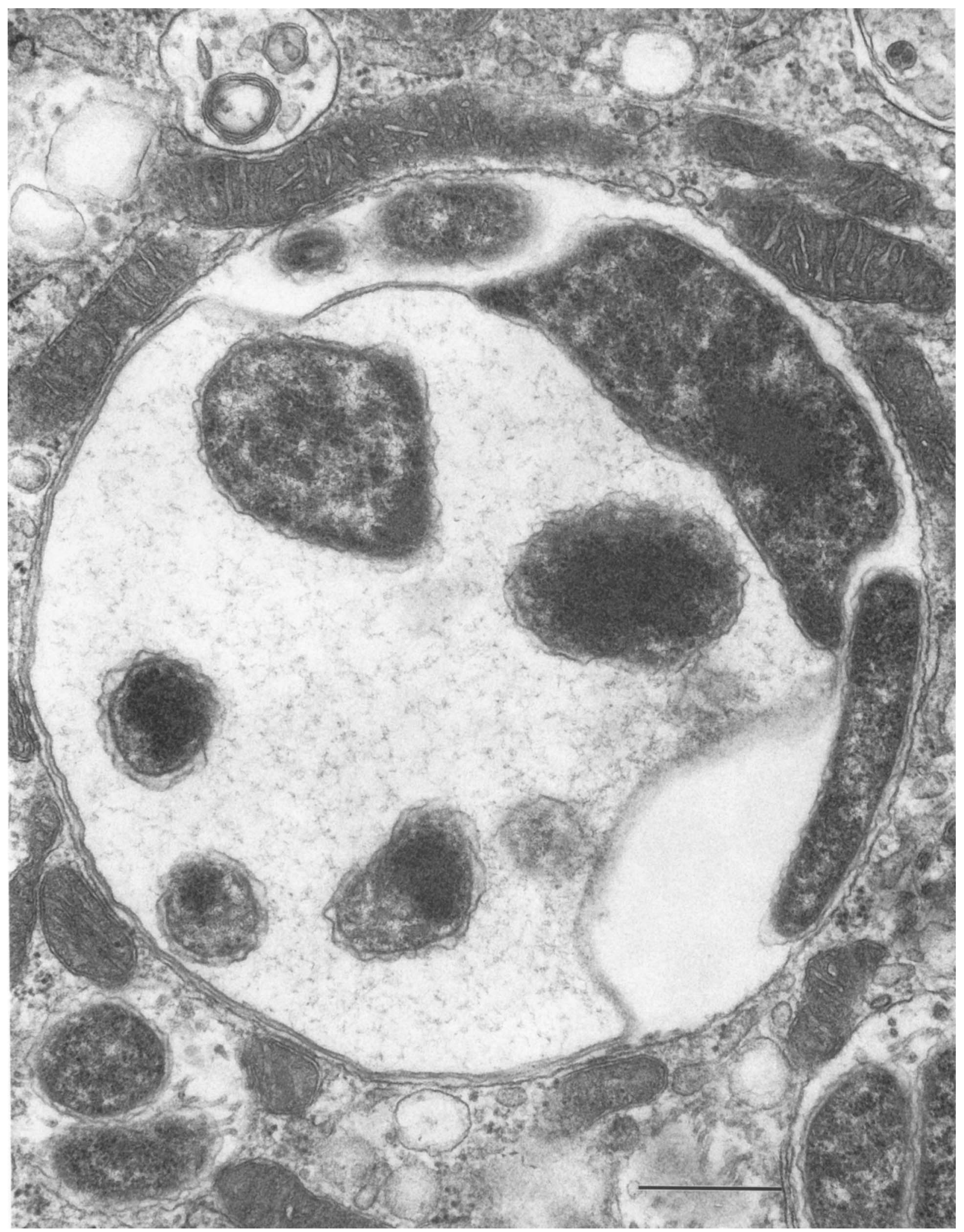

Fig. 2. An aberrant reticulate cell forming a long projection of the cell wall surrounding other ehrlichiae inside the morula. A rod-shaped reticulate cell is located along the vacuolar membrane. The morula membrane is tightly apposed by mitochondria. Irradiated mouse embryo cell (inoculum dilution $10^{2}$ ). Bar $=0.5 \mu \mathrm{m}$.

cells had a bacillary shape that in some organisms was elongated. This first type of ehrlichia had two membranes-a smooth-contoured cytoplasmic membrane and a cell wall membrane that usually had a wavy appearance, leaving some space between them that corresponded to the periplasmic space of other bacteria (fig. 1). Morphologically, those cells were similar to chlamydial reticulate bodies, so they are referred to descriptively as "reticulate cells". The second type of cell was usually round, sometimes oval 


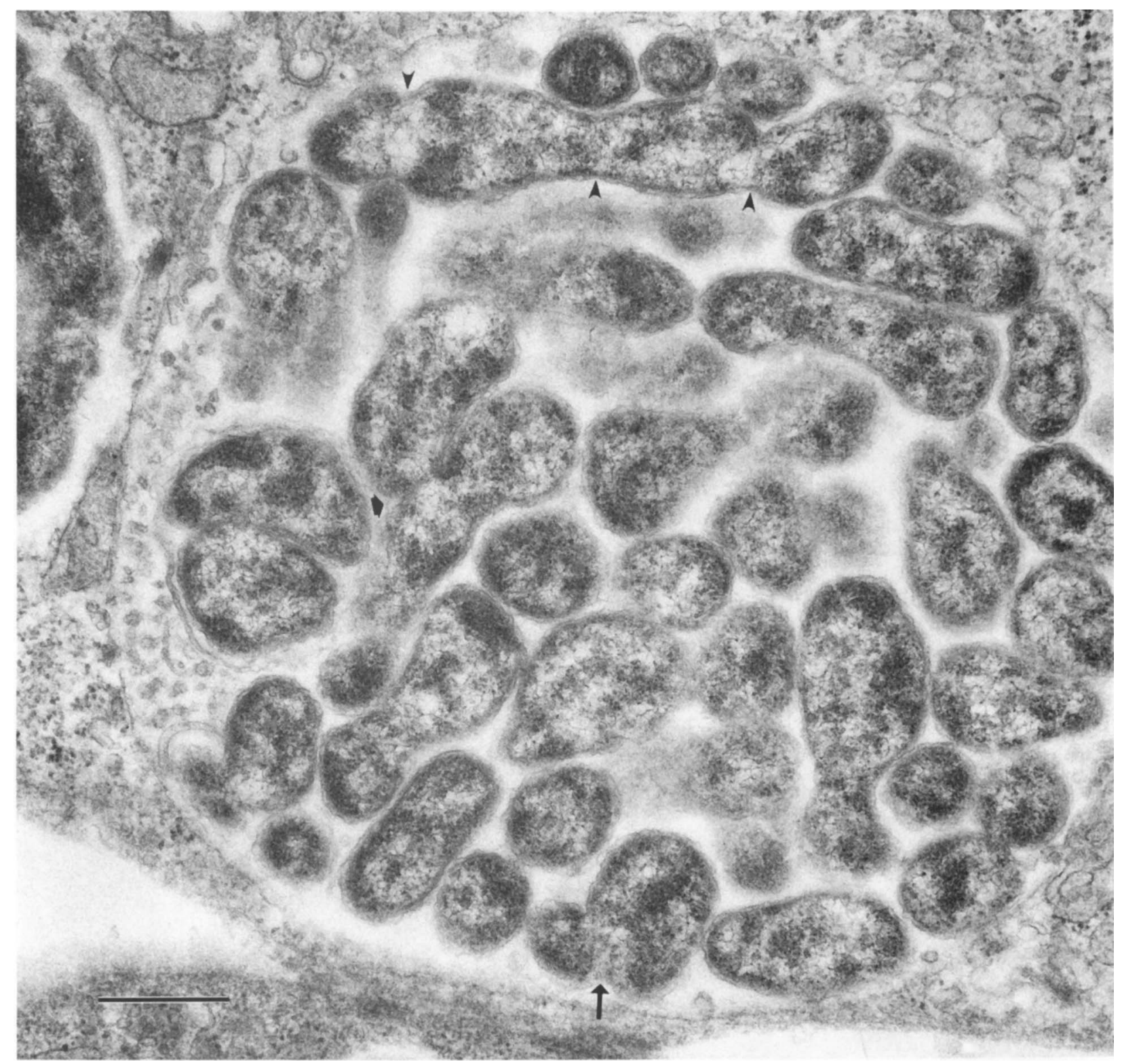

Fig. 3. A morula in the cytoplasm of a mouse embryo cell (inoculum dilution $10^{2}$ ) contains ehrlichiae with apparently impaired fission. A long cell with several constrictions $(\longrightarrow$ ), cells with unequal fission $(\rightarrow)$, or unseparated reticulate cells $(\downarrow)$. Bar $=0.5 \mu \mathrm{m}$.

or irregularly shaped, and had two limiting membranes of the same morphology as reticulate cells. They contained a central electron-dense condensation; thus, they are designated descriptively as "dense-cored cells". Their diameter was usually $0 \cdot 4-0 \cdot 6 \mu \mathrm{m}$ (fig. 1).

Ehrlichiae with apparently distinct alterations from normal were not uncommon in the intramorular ehrlichial population and were observed in all five cell lines. The ehrlichial structural abnormalities detected could be grouped into at least seven distinct types. (1) Dense-cored cells were observed with extensions of the cell wall and enlarged periplasmic space. They resembled spheroplasts of other bacteria and were found usually extracellularly in the near vicinity of the host cells or in vacuoles. (2) Enlarged reticulate cells, some of them having an irregular shape, forming long projections of the cell wall. In some morulae, those projections surrounded other ehrlichiae inside the morula cavity (fig. 2). Sometimes the projection was obviously formed by both ehrlichial membranes and contained a thin layer of cytoplasm. (3) Large multilobular reticulate cells seemed to have formed as a result of uncompleted or impaired fission (figs. 3 and 4A). One such cell could occupy an entire morula. (4) Enlarged reticulate cells $(1 \cdot 5-2.0 \mu \mathrm{m})$ were noted to contain vacuoles within the ehrlichial cytoplasm lined by a single membrane (fig. 4B). (5) A portion of the reticulate and dense-cored cells contained intracytoplasmic invaginations of the cytoplasmic membrane. The invaginations were of different lengths and separated the ehrlichial cytosol into two or more unequal, incompletely segregated compartments (fig. 4C). (6) Some reticulate cells contained small cytoplasmic membrane-bound fragments, having a diameter of $50-150 \mathrm{~nm}$, in the periplasmic space. In a single plane of section, a reticulate cell showed 1-20 such fragments in the periplasmic space. The fragments appeared to be in the process of budding from 

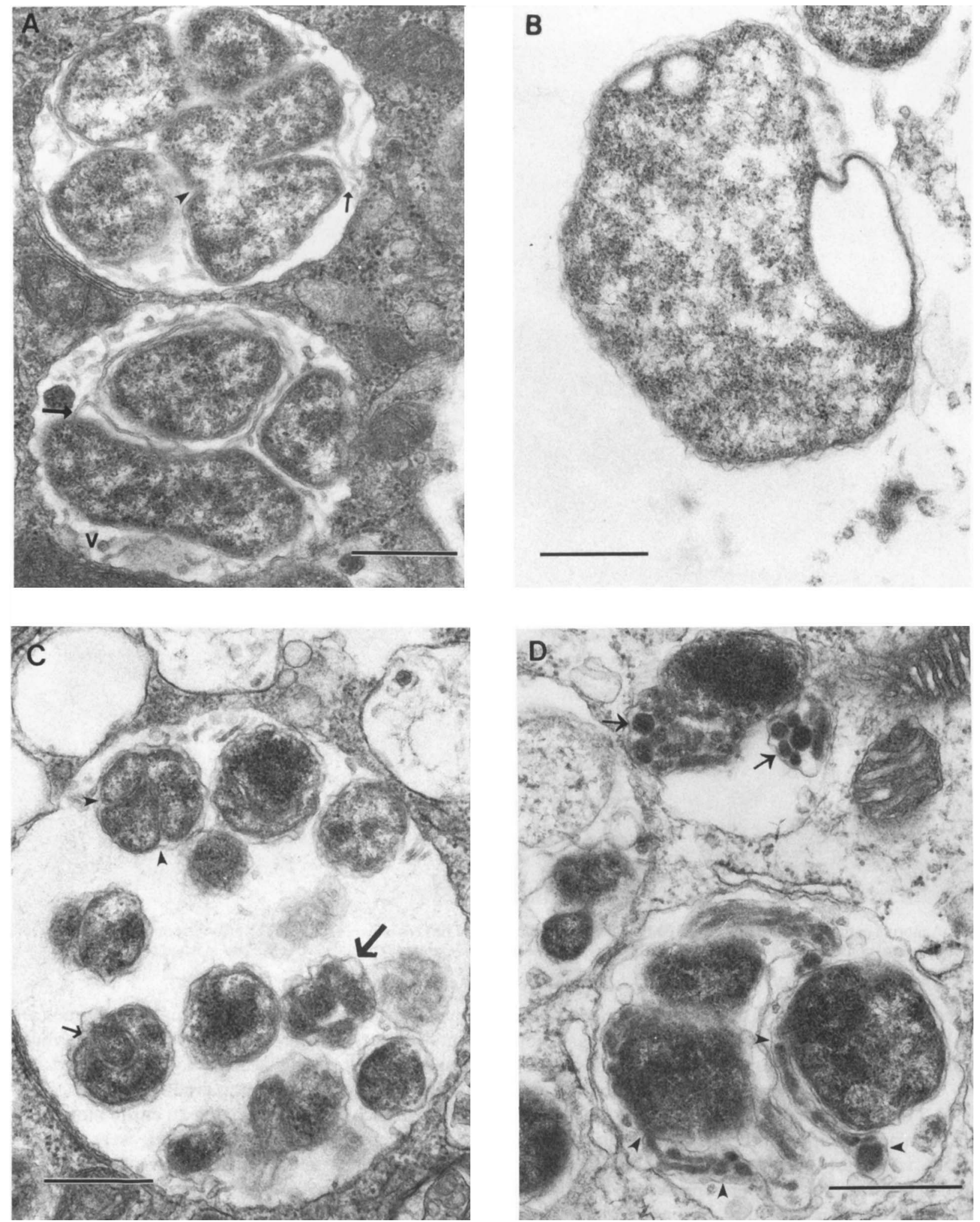

Fig. 4. Aberrant ehrlichiae inside the morulae in different cell lines. Bars $=0.5 \mu \mathrm{m}$. A. Reticulate cells with impaired fission $(\square)$; intramorular tubules $(\rightarrow)$ and vesicles (v) in an L929 cell (inoculum dilution 10). B. Large vacuolated reticulate ehrlichia in a Vero cell (inoculum dilution $10^{2}$ ). C. Small reticulate-type cell with the protoplast subdivided by invaginations of cytoplasmic membrane ( $\rightarrow$ ), an ehrlichial cell with fragmented protoplast $\rightarrow$ ) and a dense-cored type cell with an invagination of cytoplasmic membrane $(\rightarrow)$ in an irradiated mouse embryo cell (inoculum dilution 10). D. Protoplast fragments (minute forms) inside expanded periplasmic space $(\rightarrow)$ and long, thick cell wall projections $(-)$ in large reticulate cells in an irradiated mouse embryo cell (inoculum dilution $10^{3}$ ).

the protoplast into the periplasm (fig. 4D). Those fragments were similar to minute forms described previously in chlamydiae. (7) Large cells with the shape of large reticulate cells contained intra- cytoplasmic conglomerates of dense materials and ribosomes resembling the condensations observed in dense-cored cells. Some of these cells were vacuolated or had periplasmic buds. They were usually found 


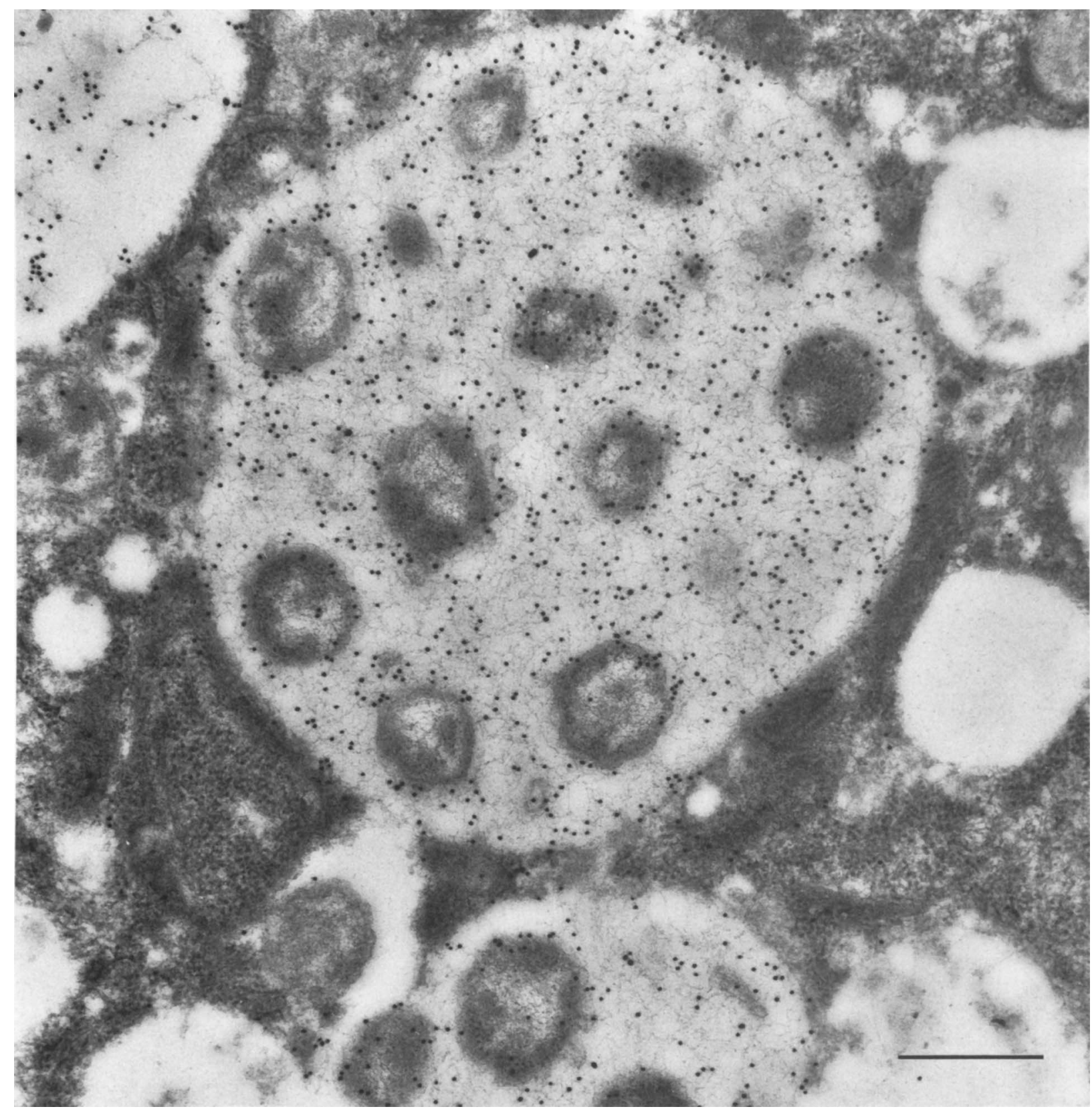

Fig. 5. Portions of three morulae in the cytoplasm of a DH82 cell (undiluted cell-free inoculum), showing intense immunogold labelling of intramorular fibrils and the periphery of ehrlichial cells with polyclonal canine anti-E. chaffeensis serum. Bar $=0.5 \mu \mathrm{m}$.

inside the morulae with apparently degenerating ehrlichiae.

\section{Morphology of ehrlichial morulae}

Four types of ehrlichial morulae could be seen in infected cells, all of them having a round shape. (1) Small morulae (1.0-1.5 $\mu \mathrm{m}$ in diameter) contained few (from one to five) reticulate cells. The ehrlichiae within such a single morula frequently varied in diameter. (2) Large morulae $(2 \cdot 0-4 \cdot 0 \mu \mathrm{m}$ in diameter) often contained many reticulate cells that were more uniform in size. Some of the ehrlichiae were observed in the process of dividing by binary fission (fig. 1). (3) Large morulae of the same size as those described or larger (up to $5.0 \mu \mathrm{m}$ ), contained both reticulate and densecored ehrlichiae. (4) Other large morulae $(4 \cdot 0-6 \cdot 0 \mu \mathrm{m})$ contained only dense-cored ehrlichiae (fig. 1).
Usually ehrlichiae inside the morula were packed rather loosely, but in some cells morulae with densely packed intact bacteria were encountered. In most instances, the spaces between dense-cored cells appeared larger. These spaces were often filled with membrane-bound vesicles that were $60-300 \mathrm{~nm}$ in diameter and tubules $25 \mathrm{~nm}$ in diameter and up to $1.5 \mu \mathrm{m}$ long. The latter were formed by two membranes with a narrow space between them and seemed to originate from the cell wall of reticulate cells. The vesicles were frequently observed in connection with the surface of those cells (fig. 4A).

The intramorular matrix was in some morulae filled with fibrillar material (figs. 1 and 2), that appeared to be ehrlichial antigen on staining with canine anti-E. chaffeensis serum and protein A-colloidal gold conjugate (fig. 5). Some individual host cells harboured only one type of morula, usually containing only 

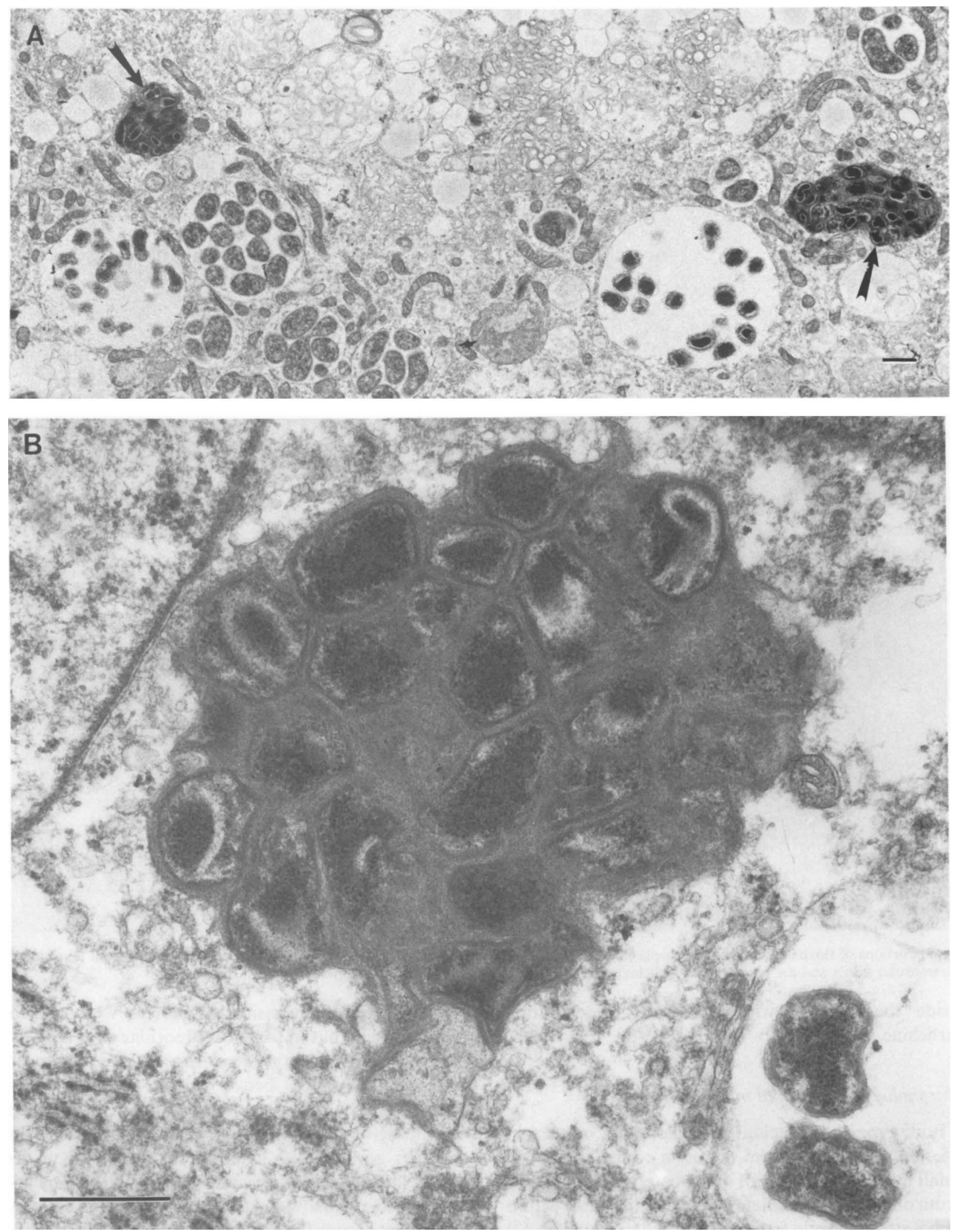

Fig. 6. Intracytoplasmic degeneration of ehrlichiae. A. Portion of host cell cytoplasm of an irradiated L929 cell (inoculum dilution 10) with morulae containing normal reticulate or dense-cored cells and adjacent morulae with dense degenerating ehrlichiae $(\leftarrow)$. Bar $=1 \mu \mathrm{m}$. B. A dense morula with apparently degenerating ehrlichiae alongside one containing normal dense-core cells in an irradiated Vero cell (inoculum dilution 10). Bar $=0.5 \mu \mathrm{m}$.

reticulate cells or only dense-cored cells, whereas other cells contained all four morular types.

In addition to these four types of morulae, two different kinds of damaged ehrlichial microcolonies within the same host cell were observed along with the other morular types : the first contained ehrlichiae with apparently disorganised cytoplasmic contents and enlarged periplasmic space, many concentric mem- 
branes, some of which surrounded ehrlichiae, and large empty vesicles which appeared to represent the cross-sections of enlarged periplasmic spaces. Morulae of the second type contained altered ehrlichiae, often of irregular shape, with dense cytoplasm, and a disorganised nucleoid. These ehrlichiae were densely packed within an intramorular matrix of high density. The outlines of those morulae often were irregular (fig. 6). By morphological criteria, ehrlichiae inside those morulae were obviously injured and degenerating. In some cells, morulae with a morphology intermediate between those two kinds were seen, suggesting that gradual destruction of ehrlichiae was accompanied by progressively increased density of the morular contents.

\section{Multiplication of ehrlichiae}

Reticulate cells usually divided by binary fission into two equal-sized daughter cells. Sometimes long ehrlichial cells with several constrictions were seen, suggesting that the division process was impaired (fig. 3). Large multilobular reticulate cells (figs. 3 and 4A) appeared to result from impairment of fission. Dividing dense-cored cells were also observed, but less frequently than dividing reticulate cells.

\section{Host-cell response and cytopathology of ehrlichia- infected cells}

The most frequently observed response of the host cell to ehrlichial infection was accumulation of mitochondria around the morulae. Mitochondria were observed closely apposed to the morular limiting membrane of the host cell, following its contour, and elongated mitochondria were frequently noted to be in contact with two or more neighbouring morulae (fig. 1).

The apposition of cisterns of granular endoplasmic reticulum to the surface of the morular membrane was also regularly observed. Usually those cisterns were flattened along the circumference of the morula leaving a narrow space (5-8 $\mathrm{nm}$ wide) between the morular limiting membrane and that of the endoplasmic reticulum (fig. 1). Some of those cisterns were devoid of ribosomes.

Some infected cells were vacuolated, but the vacuoles were usually located outside the zone where morulae were concentrated. Some of the vacuoles contained vesicles, membrane profiles or fibrillar material. In some cells autophagocytic vacuoles contained portions of the host cell cytoplasm including mitochondria and cisterns of granular endoplasmic reticulum.

\section{Discussion}

Ehrlichiae are usually described as pleomorphic bacteria, but actually two types of ehrlichial cells are predominant within bacteria-containing vacuoles-reticulate and dense-cored cells. These ehrlichiae differ in their ultrastructural morphology: reticulate cells have ribosomes and DNA fibrils evenly distributed throughout the cytoplasm whereas in dense-cored cells, these components are concentrated in the central part of the cell. The functional significance of the dense core is not clear. It has been suggested that the existence of two cell types is evidence of a developmental cycle in ehrlichiae, ${ }^{22}$ but the observation of dense-cored cells undergoing binary fission by us and others ${ }^{18}$ casts doubt upon the hypothesis that only one of these morphological types is specialised for replication. It seems more likely that those cells might represent different stages of the growth cycle of ehrlichiae, logarithmic and stationary. Those stages in rickettsial ${ }^{23}$ and other gram-negative bacterial growth can differ in ultrastructure and may also differ functionally, ${ }^{24}$ such as in their ability to attach to the cells or extracellular matrix of the host ${ }^{25}$ and to enter the host cell. ${ }^{26}$

Besides these apparently physiological variations, various abnormalities were observed in the ehrlichial structures, mostly in reticulate cells. Large, or even giant, organisms showed projections of the cell wall membrane, protrusions of cytoplasmic membrane into the periplasmic space, and budding of protoplast fragments into the periplasm. Intraperiplasmic protoplast fragments ("dense bodies") have been described previously in spheroplast-like reticulate cells of E. equi. ${ }^{17}$ These structures resembled minute forms and other changes described in chlamydiae and in other bacteria during the L-transformation process. ${ }^{27,28}$ We consider these alterations to be pathological, but we do not know whether they lead to the death of the "parent" reticulate cell or whether they might be reversible in that the reticulate cell might be able to continue multiplication and formation of normal infectious progeny. The stimulus for the appearance of those pathological cells is not known, but there is evidence that altered $E$. risticii organisms appear less often in vivo than when cultivated in vitro. ${ }^{14}$

E. chaffeensis organisms form microcolonies inside cellular vacuoles (morulae) that can harbour many individual ehrlichiae. The same type of morula has been described in $E$. canis $^{16,29}$ and $E$. equi. ${ }^{18}$ In contrast, E. risticii ${ }^{18,19}$ and $E$. sennetsu ${ }^{14,30}$ tend to form small morulae, in which individual or few reticulate or dense-cored cells are located. Morulae of $E$. chaffeensis were noted to harbour reticulate cells only, dense-cored cells only, or both cell types. In all morulae of $E$. chaffeensis, ehrlichiae were distributed through the entire volume of the vacuole. There was no preferential peripheral location of reticulate cells in close apposition to the morula membrane, as has been described for E. risticii. ${ }^{14,18}$

The intramorular matrix was often filled with vesicles of varied sizes and tubules apparently originating from the cell wall of reticulate cells and fibrillar material, which was demonstrated immuno-ultra- 
structurally to be predominantly of ehrlichial origin. Vesicles were usually limited by a single membrane, and some of them were observed apparently in the process of pinching off the ehrlichial cell wall. Minicell formation as a result of impaired fission was not seen as has been described for E. risticii, ${ }^{18}$ nor was ehrlichial vacuolation observed more frequently in degenerating cells. The demonstration that the fibrillar material inside the morula was ehrlichial antigen by protein A-gold staining confirmed the explanation suggested by Rikihisa et al. ${ }^{18}$ for a similar observation in $E$. risticii, namely that the fibrillar material was produced by the ehrlichiae. Intramorular tubules have not been described previously in ehrlichiae. They were usually encountered in small morulae with reticulate cells only and resembled the cell-wall projections of other reticulate cells and presumably have the same mechanism of formation, perhaps another expression of ehrlichial injury. In some cells, especially irradiated Vero and L929 cells, the whole morula was observed to contain degenerate ehrlichiae. These morulae with injured ehrlichiae were found in host cells with no signs of injury, alongside the morulae harbouring normal reticulate and dense-cored cells. Morulae with different degrees of ehrlichial degeneration were observed, but the mechanism of this anti-ehrlichial activity remains to be determined. Fibrillar material was frequently present in morulae with severely damaged ehrlichiae.

In $E$. chaffeensis-infected host cells, a concentration of granular endoplasmic reticulum and mitochondria was usually observed adjacent to the morulae. The reason for the occasional intimate contact between these organelles and the morular membrane is not known. These features could be related to ehrlichial metabolism and resemble the host cell response to the intracytoplasmic development of chlamydiae that multiply within membrane-bound vacuoles (inclusions) and, unlike ehrlichiae, are strict energy parasites. ${ }^{28}$ Intracellular infection with $E$. chaffeensis did not cause significant cytopathology, until the late stage of intracellular infection. The cytoplasm of the infected host cell was occasionally vacuolated, but usually vacuoles were situated outside the zone of concentration of morulae. Autophagosomes were observed in some cells. Heavily infected cells were more often observed to be necrotic, particularly in cytopathic foci. These results demonstrate that $E$. chaffeensis not only multiplies inside the host cells, forming normally two types of cells, reticulate and dense-core cells, but also develops certain pathological alterations and, at times, is destroyed within the morula. The pathogenic mechanism by which ehrlichiae injure the host cell and the host defences by which intracellular ehrlichiae are killed provide important subjects of future investigation.

We are grateful to Darlene Coleman and Dora Salinas for assistance in preparation of the manuscript and to Violet Han for expert technical contributions in electronmicroscopy. This research was supported by grant (AI31341) from the National Institute of Allergy and Infectious Diseases.

\section{References}

1. Ristic M, Huxsoll DL. Ehrlichiae. In: Krieg NR, Holt JG (eds) Bergey's Manual of systematic bacteriology, vol 1 . Baltimore, Williams and Wilkins Co. 1984: 704-709.

2. Anderson BE, Dawson JE, Jones DC, Wilson KH. Ehrlichia chaffeensis, a new species associated with human ehrlichiosis. J Clin Microbiol 1991; 29 : 2838-2842.

3. Anderson BE, Greene CE, Jones DC, Dawson JE. Ehrlichia ewingii sp. nov., the etiologic agent of canine granulocytic ehrlichiosis. Int J Syst Bacteriol 1992; 42: 299-302.

4. Rikihisa Y. The tribe Ehrlichieae and ehrlichial diseases. Clin Microbiol Rer 1991; 4: 286-308.

5. Wen B. Rikihisa $\mathrm{Y}$, Mott $\mathbf{J}$ et al. Ehrlichia muris sp. nov., identified on the basis of 16S rRNA base sequences and serological, morphological, and biological characteristics. Int J Syst Bacteriol 1995; 45: 250-254.

6. Chen S-M. Dumler JS, Bakken JS, Walker DH. Identification of a granulocytotropic Ehrlichia species as the etiologic agent of human disease. J Clin Microbiol 1994; 32 : 589-595.

7. Dawson JE, Candal FJ, George VG, Ades EW. Human endothelial cells as an alternative to DH82 cells for isolation of Ehrlichia chaffeensis, E. canis, and Rickettsia rickettsii. Pathobiology 1993; 61: 293-296.

8. Rikihisa Y. Growth of Ehrlichia risticii in human colonic epithelial cells. In: Hechemy KE, Paretsky D, Walker DH, Mallavia LP (eds) Rickettsiology: current issues and perspectives. Ann NY Acad Sci 1990; 590: 104-110.

9. Rikihisa Y, Pretzman CI, Johnson GC, Reed SM, Yamamoto $S$. Andrews $F$. Clinical, histopathological and immunological responses of ponies to Ehrlichia sennetsu and subsequent Ehrlichia risticii challenge. Infect Immun 1988. 56: $2960-2966$

10. Minamishima Y. Persistent infection of Rickettsia sennetsu cell culture system. Jpn J Microbiol 1965; 9: 75-86.

11. Brouqui P, Birg ML, Raoult D. Cytopathic effect, plaque formation, and lysis of Ehrlichia chaffeensis grown on continuous cell lines. Infect Immun 1994; 62: 405-411.

12. Chen S-M, Popov VL, Feng H-M, Wen J, Walker DH. Cultivation of Ehrlichia chaffeensis in mouse embryo, Vero, BGM, and L929 cells and study of Ehrlichia-induced cytopathic effect and plaque formation. Infect Immun 1995; 63: 647-655

13. Anderson DR, Hopps HE, Barile MF, Bernheim BC. Comparison of the ultrastructure of several rickettsiae, ornithosis virus, and mycoplasma in tissue culture. $J$ Bacteriol $1965 ; 90: 1387-1404$.

14. Rikihisa $Y$. Ultrastructure of rickettsiae with special emphasis on ehrlichiae. In: Williams JC, Kakoma J (eds) Ehrlichiosis: a vector-borne disease of animals and humans. Dordrecht, Kluwer Academic Publishing. 1990: 22-31

15. Hildebrandt PK, Conroy JD, McKee AE, Nyindo MBA, Huxsoll DL. Ultrastructure of Ehrlichia canis. Infect Immun 1973; 7: 265-271.

16. Smith RD, Sells DM, Stephenson EH, Ristic M, Huxsoll DL. Development of Ehrlichia canis, causative agent of canine ehrlichiosis, in the tick Rhipicephalus sanguineus and its differentiation from a symbiotic rickettsia. Am J Vet Res 1976; 37: 119-126.

17. Sells DM, Hildebrandt PK, Lewis GE, Nyindo MBA, Ristic M Ultrastructural observations on Ehrlichia equi organisms in equine granulocytes. Infect Immun 1976; 13: 273-280.

18. Rikihisa Y, Perry BD, Cordes DO. Ultrastructural study of ehrlichial organisms in the large colons of ponies infected with Potomac horse fever. Infect Immun 1985; 49: 505-512.

19. Wells MY, Rikihisa Y. Lack of lysosomal fusion with phagosomes containing Ehrlichia risticii in P388D, cells: abrogation of inhibition with oxytetracycline. Infect Immun 1988; 56: 3209-3215.

20. Ito S, Rikihisa Y. Techniques for electron microscopy of 
rickettsiae. In: Burgdorfer W, Anacker RL (eds) Rickettsiae and rickettsial diseases. New York, Academic Press Inc. 1981: 213-227.

21. Berryman MA, Rodewald RD. An enhanced method for postembedding immunocytochemical staining which preserves cell membranes. J Histochem Cytochem 1990; 38: 159-170.

22. Ristic M. Current strategies in research on ehrlichiosis. In: Williams JC, Kakoma J (eds) Ehrlichiosis: a vector-borne disease of animals and humans. Dordrecht, Kluwer Academic Publishing. 1990: 136-153.

23. Silverman DJ, Wisseman CL, Waddell A. In vitro studies of rickettsia-host cell interactions: ultrastructural study of Rickettsia prowazekii-infected chicken embryo fibroblasts. Infect Immun 1980; 29: 778-790.

24. Falkow S, Isberg RR, Portnoy DA. The interaction of bacteria with mammalian cells. Annu Rev Cell Biol 1992; 8: 333-363.

25. Finlay BB, Heffron F, Falkow $S$. Epithelial cell surfaces induce Salmonella proteins required for bacterial adherence and invasion. Science $1989 ; 243$ : 940-943.
26. Lee CA, Falkow S. The ability of Salmonella to enter mammalian cells is affected by bacterial growth state. Proc Natl Acad Sci USA 1990; 87: 4304-4308.

27. Hatten BA, Schmitt-Slomska J. Brucella L-forms-their occurrence and characteristics. In: Madoff $S$ (ed) The bacterial L-forms. New York, Marcell Dekker. 1986: 163-184.

28. Avakyan AA, Popov VL. Rickettsiaceae and Chlamydiaceae: comparative electron microscopic studies. Acta Virol 1984; 28: 159-173.

29. Nyindo M, Holland CJ, Kakoma J. Current status of the in vitro cultivation of ehrlichia. In: Williams JC, Kakoma $\mathbf{J}$ (eds) Ehrlichiosis: a vector-borne disease of animals and humans. Dordrecht, Kluwer Academic Publishing. 1990: 9-21.

30. Popov VL, Chen S-M, Wen JW, Dumler JS, Feng H-M, Walker DH. Morphological variation of Ehrlichia chaffeensis and E. sennetsu: evidence for ehrlichial pathology. Abstract, 11th Meeting of ASSRD, September 17-20, 1994. 